\title{
Shifts in the arbuscular mycorrhizal fungal community composition of Betula alnoides along young, middle-aged plantation and adjacent natural forest
}

\author{
Yuebo Jing ${ }^{(1-2)}$, \\ Tao Li ${ }^{(1)}$, \\ Hongliang $\mathrm{Cui}^{(3)}$, \\ Lingfei $\mathbf{L i}^{(4)}$, \\ Samuel C Allen ${ }^{(5)}$, \\ Lin Chen ${ }^{(1)}$, \\ Yongpeng $\mathrm{Li}^{(2)}$, \\ Zhiwei Zhao ${ }^{(1)}$
}

Betula alnoides is a fast-growing and native timber species prevalently planted in tropical and subtropical areas of southern China. Despite the large-scale development of $B$. alnoides plantations, knowledge of its association with arbuscular mycorrhizal fungi (AMF) is limited. In the present study, we chose young (3-year-old sapling, P3y) and middle-aged (12-year-old stand, P12y) B. alnoides plantations and adjacent native forest $(\mathrm{N})$ in the Puwen Tropical Forest Experimental Station located in Xishuangbanna prefecture of Yunnan Province, southwestern China, as study materials and explored the change in AMF community composition in the plantation chronosequence. In addition, we combined morphological methods and Illumina MiSeq sequencing techniques to analyze rhizosphere soil AMF. The results indicated that the AMF richness and diversity indexes of $B$. alnoides at two ages tended to be similar to those of natural growing trees in native forest. However, the specific AM fungal compositions were distinctly different, providing evidence of the conservation value of the native forest, which harbors a unique AMF diversity. Hierarchical cluster analysis further revealed that the AMF community composition of trees in the mid-aged stand (P12y) was more similar to that of naturally growing $B$. alnoides $(\mathrm{N})$ than that of the young-aged trees (P3y), which proved the considerable resilience of AMF to the establishment of the $B$. alnoides plantation. A set of at least five soil properties (available phosphorus, available nitrogen, organic matter, total nitrogen and silt content) was found to play a significant role in shaping the AMF communities. These results contribute to the understanding of the impacts of $B$. alnoides plantations on AMF diversity and composition. Such information is critical for the efficient planting and sustainable management of $B$. alnoides plantations.

(1) Laboratory of Conservation and Utilization for Bioresources and Key Laboratory of Microbial Diversity in Southwest China, Ministry of Education, Yunnan University, Kunming, 650091 Yunnan (China); (2) Yunnan Academy of Forestry and Grassland, Kunming, 650201 Yunnan (China); (3) Yunnan Reascend Tobacoo Technology (group) Co., Ltd., Kunming, 650106 Yunnan (China); (4) College of Food Science and Technology, Yunnan Agricultural University, Kunming, 650201 Yunnan (China); (5) Department of Plant and Environmental Sciences, Agricultural Science Center, New Mexico State University, Farmington, NM 87401 (USA)

\section{@ Zhiwei Zhao (zhaozhw@ynu.edu.cn)}

Received: May 15, 2020 - Accepted: Aug 04, 2020

Citation: Jing Y, Li T, Cui H, Li L, Allen Samuel C, Chen L, Li Y, Zhao Z (2020). Shifts in the arbuscular mycorrhizal fungal community composition of Betula alnoides along young, middle-aged plantation and adjacent natural forest. iForest 13: 447-455. - doi: 10.3832/ifor3515-013 [online 2020-1007]

Communicated by: Werther Guidi Nissim
Keywords: Arbuscular Mycorrhizal Fungi, Betula alnoides, Plantation, Native Forest

\section{Introduction}

Significant levels of biodiversity and ecosystem services of tropical forests are of global importance. However, due to human population growth and increasing demand for agricultural products, the conversion of natural forest to agricultural land has been increasing worldwide in recent decades. It was estimated that $68,000 \mathrm{~km}^{2}$ of tropical forest is lost annually, and this amount is increasing by $3 \%\left(>2000 \mathrm{~km}^{2}\right)$ each year (Hansen et al. 2013). Presently, agroforestry and human-made forests using fast-growing native species for the purposes of timber and non-timber products are the sustainable alternatives to satisfy the high increasing demand and relieve pressure on primary tropical forests (Jacobs et al. 2015).

Betula alnoides Buch. Ham. ex D. Don (a birch species) is the only species in the genus Betula that has been found naturally in the tropics. It is a valuable tree species mainly distributed in southeastern Asia and southern China with good adaptability to a wide range of soil conditions. The wood of B. alnoides has moderate density with optimal texture, is resistant to cracking and warping, and is predominantly used for flooring, in high-grade furniture and interior decoration. Artificial planting of B. alnoides in southern China began in the 1980 , and the planting areas have exceeded 150,000 ha, mainly in Yunnan and Guangdong provinces (Wang et al. 2016).

Along with the large-scale establishment of B. alnoides plantations in southern China, some concerns have been paid to the stability and sustainability of this artificial forest from different ecological aspects, including plant community diversity, soil physicochemical properties, carbon sequestration, and soil and water conservation (Jiang et al. 1999, Meng et al. 2002, Li et al. 2003, Chen et al. 2006). However, the study of microorganisms in this forest is quite limited. Among the rhizosphere microbial communities, arbuscular mycorrhizal fungi (AMF) are one of the most critical components; AMF are obligate root symbionts associated with approximately $72 \%$ of vascular plants (Brundrett \& Tedersoo 2018) and occur in almost every terrestrial ecosystem (Smith \& Read 2008). AMF are known to provide a wide range of ecosystem functions, including improving 
plant productivity through increased nitrogen and phosphorus acquisition, enhanc ing drought tolerance and protecting host plants from soil pathogens (Smith \& Read 2008). AMF not only play critical roles in determining the performance of host species (Van Der Heijden et al. 1998) but also enhance the sustainability of ecosystems by improving soil structure (Rillig \& Mummey 2006). Furthermore, since they can reflect the different levels of degradation and the changes during vegetation recuperation, AMF are correlated with the veg etation type and can notably reveal the rate of soil development; therefore, the AM fungal community is considered to be a good soil quality indicator (Pagano et al. 2011).

Previous studies reported that arbuscular mycorrhizal symbiosis significantly promoted the growth, nutrient absorption and photosynthesis of $B$. alnoides seedlings in greenhouse experiments (Gong et al. 2000). There is evidence that afforestation significantly affects the development, dis tribution, and function of the AM funga community composition (Guo \& Han 2008 Sheng et al. 2017). However, studies focusing on $\mathrm{AM}$ symbiosis and the composition of AMF communities in B. alnoides forests have yet to be conducted, which is critical as the first step towards the managemen and application of AMF communities aimed at improving the health of the soil to promote the productivity and sustainability of B. alnoides plantations.

The present study was conducted at the Puwen Tropical Forest Experimental Station located in Xishuangbanna Prefecture of Yunnan Province, southwestern China. Xishuangbanna is an Indo-Burma biodiversity hotspot and comprises $16 \%$ of the total plant diversity in China (Cao et al. 2006) The forests in this area have a biodiversity that is important both globally and nation ally. Therefore, more studies concerning the conservation of biodiversity are need ed to provide information and enhance the understanding of this specific forest ecosystem.

We selected young (3-year-old saplings, P3y) and middle-aged (12-year-old stand, $P 12 y)$ B. alnoides plantations and adjacent native forest $(\mathrm{N})$ at the same slope as the study targets. The primary objectives were (i) to study the AM symbiosis of B. alnoides in the forest, (ii) to assess to what extent B. alnoides plantation affects AM fungal composition and diversity by illuminating the shifts in different growing stages and comparing them with naturally growing $B$. alnoides trees in native forest, and (iii) to explore the soil properties affecting the shift in AMF communities after afforestation with $B$. alnoides.

\section{Materials and methods}

\section{Site description and sampling}

The study site is located in the Puwen Tropical Forest Experimental Station of
Yunnan Academy of Forestry and Grassland, Yunnan Province, China (101 $01^{\circ} \mathrm{E}, 22^{\circ}$ $25^{\prime} \mathrm{N}, 800-1354 \mathrm{~m}$ a.s.l.). This area belongs to the northern margin of the tropics in the Northern Hemisphere. The topology of this area is characterized by low mountains and hills, and the soil type is lateritic red soil. The climate is tropical monsoon, with a mean annual temperature of $20.2{ }^{\circ} \mathrm{C}$ and mean maximum and minimum temperatures of $23.9^{\circ} \mathrm{C}$ (July and August) and 13.8 ${ }^{\circ} \mathrm{C}$ (January), respectively. The annual rainfall $(1675.5 \mathrm{~mm} \mathrm{ca}$.) is mostly concentrated (86\%) in the warm season (May-October). The zonal vegetation includes montane rainforest, monsoon evergreen broadleaved forest, wet seasonal forest and ravine rainforest (Wang et al. 2003). B. alnoides plantations were initially established in this area in 1988, and the Puwen Tropical Forest Experimental Station contains stands of different ages. To reduce the effect of geographical distance on AMF, two B. alnoides plots, 3-year-old (P3y) and 12year-old plantation (P12y), close to each other (with a distance of less than $100 \mathrm{~m}$ ) and a plot of natural stand $(\mathrm{N})$ with $\mathrm{B}$. alnoides trees adjacent to the plantation were selected; the selected plots were at the same slope. Thus, the study serves as a specific case for exploring the AMF recruited by B. alnoides at different growing stages. Sampling was conducted in October 2018. Five B. alnoides trees from each plot were chosen randomly, totalling 15 selected trees. For each B. alnoides sample, the fine roots and rhizosphere soil from four directions (east, west, south and north) were collected, mixed and homogenized into a homogenous sample. To ensure identity of each sample, we followed each root to their origin and distinguished the $B$. alnoides roots by observing the dark red color of the velamen and the peculiar smell.

The average diameters at breast height (DBH) of sampled $B$. alnoides trees from P3y and P12y and N were 4.9, 18.7 and 36.6 $\mathrm{cm}$, respectively, which can represent the young, mediate and mature stages of B. alnoides. There was no management in the soil of the plantation (fertilization, herbicide or tillage). Only manual weeding was conducted during the first and second years of planting.

\section{Soil characteristics analysis}

The soil samples were air-dried and homogenized by sieving through a 2-mm mesh to remove plant debris and coarse sand. Particle-size analysis was conducted with the pipette method according to the U.S. Department of Agriculture system (Singer M \& Janitzky 1986) to examine the soil texture. Soil enzyme activities were determined using the enzyme activity assay kits (Suzhou Comin Biotechnology Co., Ltd., Jiangsu, China) according to the manufacturer's protocol. The chemical properties of soils were analyzed using the methods described by Du et al. (2006).
Analyses of AM fungal colonization, spore density and morphological identification

Root segments were cleared with $10 \%(\mathrm{w} /$ v) $\mathrm{KOH}$ at $90{ }^{\circ} \mathrm{C}$ in a water bath for $60-90$ min. After cooling to room temperature, root samples were washed with water, cut into segments approximately $1 \mathrm{~cm}$ in length, stained with $0.5 \%$ blue ink (Hero ${ }^{\circledR}$ 203, Shanghai, China), mounted on microscope slides and examined for AM fungal structures under a compound light microscope (Olympus BX53 $3^{\oplus}$, Tokyo, Japan). Fungal colonization was measured by the magnified intersection method (McGonigle et al. 1990). The percentages of root length with hyphae, vesicles, and arbuscules were quantified by examining over 200 intersections per sample.

AM fungal spore extraction was carried out by wet sieving and decanting $20 \mathrm{~g}$ of air-dried rhizosphere soil (Gerdemann \& Nicolson 1963). Following the nomenclature of genera or species proposed by Redecker et al. (2013), AMF species were identified according to Schenck \& Pérez (1990) and several specialized websites: International Culture Collection of Vesicular Arbuscular Mycorrhizal Fungi (http://invam.caf.wvu. edu/), Blaszkowski (http://www.zor.zut. edu.pl/Glomeromycota/), Schübler and Walker (http://schuessler.userweb.mwn.de lamphylo/).

\section{Soil DNA extraction, $P C R$, Illumina MiSeq sequencing and bioinformatics analysis}

Using the EZNA ${ }^{\circledast}$ Soil DNA Kit (Omega Bio-tek, Norcross, GA, USA), genomic DNA was extracted from $0.5 \mathrm{~g}$ of air-dried soil sample according to the manufacturer's protocol. The final DNA purity and concentration were determined with a NanoDrop $2000^{\oplus}$ UV-vis spectrophotometer (Thermo Scientific, Wilmington, MA, USA), and DNA quality was checked by $1 \%(w / v)$ agarose gel electrophoresis.

Nested PCR was used to improve the fragment specificity. The first PCR was performed using a combination of the AM fungal-specific primers AML1 (5'-ATCAACTTTCGATGGTAGGATAGA-3') and AML2 (5'-GAACCCAAACACTTTGGTTTCC-3' - Lee et al. 2008) with an initial denaturation at $95{ }^{\circ} \mathrm{C}$ for 3 min; 32 cycles of $95^{\circ} \mathrm{C}$ for $30 \mathrm{~s}, 55^{\circ} \mathrm{C}$ for 30 $\mathrm{s}$, and $72{ }^{\circ} \mathrm{C}$ for $45 \mathrm{~s}$; and a final extension step of $72{ }^{\circ} \mathrm{C}$ for $10 \mathrm{~min}$. The product of the first PCR amplification was used as the template DNA for the next PCR. AM fungalspecific primers AMV4.5NF (5'-AAGCTCGTAGTTGAATTTCG-3') and AMDGR (5'-CCCAACTATCCCTATTAATCAT- 3 ') were added (Lumini et al. 2010), and nested PCR was conducted with an initial denaturation at $95^{\circ} \mathrm{C}$ for $3 \mathrm{~min} ; 30$ cycles of $95{ }^{\circ} \mathrm{C}$ for $30 \mathrm{~s}, 55^{\circ} \mathrm{C}$ for $30 \mathrm{~s}$, and $72{ }^{\circ} \mathrm{C}$ for $45 \mathrm{~s}$; and a final extension step of $72{ }^{\circ} \mathrm{C}$ for 10 min. Both PCRs were carried out in $20 \mu \mathrm{L}$ of reaction mixtures containing $4 \mu \mathrm{L}$ of $5 \times$ FastPfu Buffer, $2 \mu \mathrm{L}$ of $2.5 \mathrm{mM}$ dNTPs, $0.4 \mu \mathrm{L}$ of each primer $(10 \mathrm{mM}), 0.4 \mu \mathrm{L}$ of FastPfu poly- 
merase, $1 \mu \mathrm{L}$ of template DNA (approximately $10 \mathrm{ng}$ ), $0.2 \mu \mathrm{L}$ of BSA, and $10.8 \mu \mathrm{L}$ of sterile distilled $\mathrm{H}_{2} \mathrm{O}$. An 8-bp sequence barcode was added as a tag to distinguish the $\mathrm{PCR}$ products from one another.

The amplified fragments were extracted from $2 \%$ agarose gels and purified with an AxyPrep ${ }^{\circledR}$ DNA Gel Extraction Kit (Axygen, USA) following the manufacturer's instructions and quantified using QuantiFluorTM$\mathrm{ST}^{\circledast}$ (Promega, USA). Purified amplicons were pooled in equimolar and paired-end sequenced $(2 \times 300)$ on an Illumina $\mathrm{MiSeq}^{\circledR}$ platform (Illumina, San Diego, CA, USA) according to standard protocols by Majorbio Bio-Pharm Technology Co., Ltd. (Shanghai, China).

Raw fastq files were quality-filtered by Trimmomatic and assembled by FLASH. The criteria used were as follows: (i) the reads were truncated at any site with an average quality score $<20$ over a 50 bp sliding window; (ii) sequences with overlaps longer than 10 bp were assembled, providing their overlap had less than 2 bp mismatches; (iii) sequences of each sample were separated using barcodes (exactly matching) and primers (allowing 2 nucleotide mismatches), and reads containing ambiguous bases were deleted.

Operational taxonomic units (OTUs) were clustered with a $97 \%$ similarity cutoff using UPARSE (version 7.1 - http://drive5.com/u parse/) with a novel "greedy" algorithm that performs chimera filtering and OTU clustering simultaneously. The taxonomy of each sequence was analyzed using the RDP Classifier algorithm (http://rdp.cme. msu.edu/) against the MaarjAM database with a confidence threshold of $70 \%$ (Opik et al. 2010).

\section{Statistical analysis}

Variations in soil physical, chemical and biological characteristics and AMF attributes, including AMF colonization in roots, spore density and relative abundance of morphological species identified from rhizosphere soil, and Glomeromycota OTUs in soil, were analyzed using the Kruskal-Wallis test.

To test whether the AMF composition

Tab. 1 - Soil properties of young and middle-aged Betula alnoides plantations and adjacent native forest located in Puwen Tropical Forest Experimental Station, Xishuang banna prefecture of Yunnan Province, southwestern China. P3y, P12y and N represent 3-year-old saplings, 12-year-old stands and adjacent native forests, respectively. (TN): total nitrogen; (TP): total phosphorus; (TK): total potassium; (AN): available nitrogen; (AP): available phosphorus; (AK): available potassium; (OM): organic matter; (ACP): acid phosphatase activity; (ALP): alkaline phosphatase activity; (UE): urease activity; (CAT): catalase activity; (SC): sucrase activity. Data are expressed as the mean $\pm \mathrm{SE}$ $(n=5)$. Differences at $p<0.05$ were considered statistically significant.

\begin{tabular}{|c|c|c|c|c|c|}
\hline $\begin{array}{l}\text { Soil } \\
\text { parameter }\end{array}$ & Units & P3y & P12y & $\mathrm{N}$ & $p$ \\
\hline $\mathrm{pH}$ & - & $4.64 \pm 0.04$ & $4.28 \pm 0.03$ & $4.22 \pm 0.01$ & 0.006 \\
\hline TN & $\mathrm{g} \mathrm{kg}^{-1}$ & $0.54 \pm 0.06$ & $1.18 \pm 0.05$ & $1.48 \pm 0.11$ & 0.004 \\
\hline TP & $\mathrm{g} \mathrm{kg}^{-1}$ & $0.27 \pm 0.01$ & $0.37 \pm 0.03$ & $0.38 \pm 0.01$ & 0.008 \\
\hline TK & $\mathrm{g} \mathrm{kg}^{-1}$ & $8.81 \pm 0.17$ & $12.52 \pm 0.77$ & $10.50 \pm 0.54$ & 0.008 \\
\hline AN & $\mathrm{mg} \mathrm{kg}^{-1}$ & $44.20 \pm 5.73$ & $95.93 \pm 12.55$ & $141.90 \pm 9.03$ & 0.005 \\
\hline AP & $\mathrm{mg} \mathrm{kg}^{-1}$ & $1.97 \pm 0.13$ & $2.87 \pm 0.23$ & $3.66 \pm 0.38$ & 0.005 \\
\hline$A K$ & $\mathrm{mg} \mathrm{kg}^{-1}$ & $54.50 \pm 1.66$ & $73.25 \pm 6.19$ & $105.25 \pm 19.26$ & 0.009 \\
\hline$O M$ & $\mathrm{~g} \mathrm{~kg}^{-1}$ & $11.00 \pm 1.49$ & $25.50 \pm 1.28$ & $33.96 \pm 2.40$ & 0.004 \\
\hline $\mathrm{ACP}$ & $\mu \mathrm{mol} \mathrm{d} \mathrm{d}^{-1} \mathrm{~g}^{-1}$ & $12.43 \pm 1.75$ & $11.39 \pm 0.64$ & $13.18 \pm 1.73$ & 0.827 \\
\hline ALP & $\mu \mathrm{mol} \mathrm{d}^{-1} \mathrm{~g}^{-1}$ & $2.02 \pm 0.34$ & $12.65 \pm 0.28$ & $12.65 \pm 0.28$ & 0.009 \\
\hline UE & $\mu \mathrm{g} \mathrm{d}^{-1} \mathrm{~g}^{-1}$ & $538.12 \pm 77.94$ & $1058.85 \pm 68.03$ & $964.81 \pm 38.75$ & 0.007 \\
\hline CAT & $\mu \mathrm{mol} \mathrm{d}^{-1} \mathrm{~g}^{-1}$ & $4.58 \pm 0.41$ & $25.40 \pm 1.65$ & $25.33 \pm 2.03$ & 0.009 \\
\hline SC & $\mathrm{mg} \mathrm{d}^{-1} \mathrm{~g}^{-1}$ & $17.57 \pm 2.91$ & $35.27 \pm 4.92$ & $34.47 \pm 2.00$ & 0.013 \\
\hline Sand & $\%$ & $42.40 \pm 1.36$ & $45.40 \pm 2.71$ & $47.60 \pm 1.03$ & 0.070 \\
\hline Silt & $\%$ & $16.20 \pm 0.37$ & $24.00 \pm 1.05$ & $24.60 \pm 1.69$ & 0.009 \\
\hline Clay & $\%$ & $41.60 \pm 1.57$ & $30.60 \pm 3.42$ & $27.80 \pm 1.63$ & 0.020 \\
\hline
\end{tabular}

clearly separated among different aged plantations and natural stand and to further explore the effect of soil parameters on AMF composition, we performed nonmetrical multidimensional scaling (NMDS) based on the relative abundance of morphological species and OTU matrix (OTU abundance table) using Morisita-Horn dissimilarity in the "vegan" R package (Oksanen et al. 2013). Subsequently, differences in community composition among three study stands were tested by permutational multivariate analysis of variance (PERMANOVA) with 1000 iterations performed using the package "vegan" in R. In addition, the similarity among AM fungal communities concerning the number and abundance of OTUs was determined by hierar- chical cluster analysis using Spearman approx distance. Mantel tests using Euclidean distances were conducted to understand the relationships between the AM fungal communities and environmental factors. The "ecodist" package of R version 3.2 was used (Goslee \& Urban 2007).

\section{Results}

\section{Soil characteristics}

The soil physicochemical and biological parameters showed significant differences among the 3 study plots except for acid phosphatase activity and sand percentage (Tab. 1). The soil of this area was acidic. The lowest $\mathrm{pH}$ value was found in plot $\mathrm{N}(4.22)$, while the highest $\mathrm{pH}$ value was in plot $\mathrm{P} 3 \mathrm{y}$
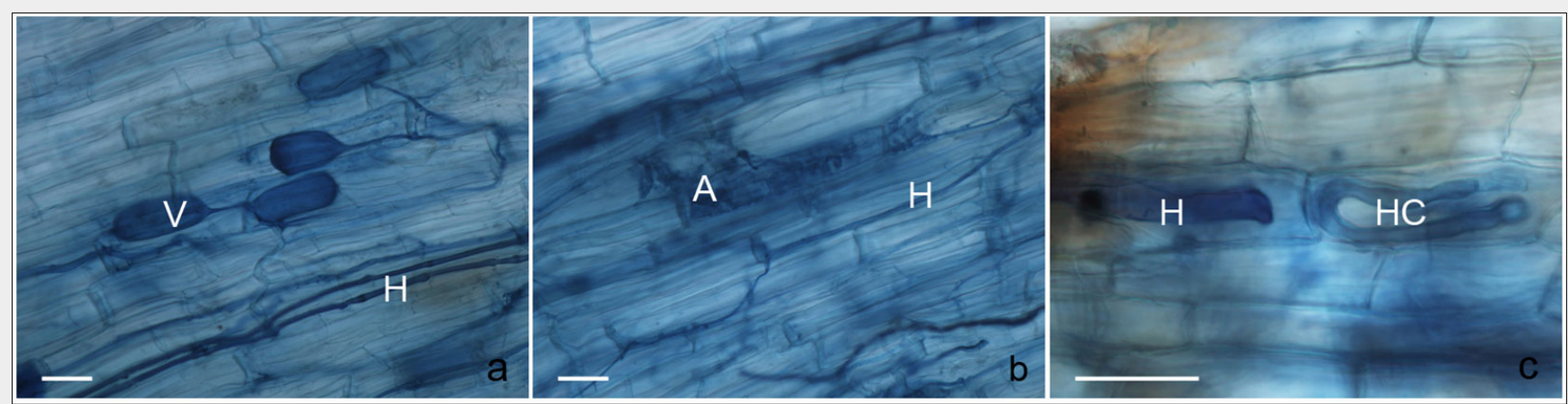

Fig. 1 - Structures of AMF colonizing the roots of Betula alnoides trees in different study stands. (a) Vesicles (V) and hyphae in the root apparatus of a 3-year-old Betula alnoides plant. (b) Arbuscules (A) and hyphae (H) are visible in the roots of 12-year-old Betula alnoides trees. (c) Hypha $(\mathrm{H})$ and hyphal coil $(\mathrm{HC})$ in the root apparatus of Betula alnoides trees growing in the native forest. Scale bar $=30 \mu \mathrm{m}$. 
Tab. 2 - AM fungal attributes of young and middle-age $d$ Betula alnoides plantations and adjacent native forest located in Puwen Tropical Forest Experimental Station, Xishuangbanna prefecture of Yunnan Province, southwestern China. P3y, P12y and N represent 3-year-old saplings, 12-year-old stand and adjacent native forest, respectively. Data are expressed as the mean $\pm \operatorname{SE}(n=5)$. Differences at $p<0.05$ were considered statistically significant.

\begin{tabular}{lcccc}
\hline Attributes & P3y & P12y & N & $p$-value \\
\hline AMF hypha colonization (\%) & $19.00 \pm 5.61$ & $25.32 \pm 2.18$ & $7.54 \pm 2.57$ & 0.044 \\
\hline Arbuscule colonization (\%) & $1.61 \pm 0.67$ & $3.84 \pm 2.17$ & $0.58 \pm 0.30$ & 0.170 \\
\hline Vesicle colonization (\%) & $15.97 \pm 5.55$ & $15.30 \pm 2.13$ & $4.16 \pm 1.44$ & 0.088 \\
\hline Spore density (no. spore/20 g soil) & $51.00 \pm 18.23$ & $98.00 \pm 37.18$ & $225.20 \pm 82.95$ & 0.054 \\
\hline Shannon index of morphospecies & $1.29 \pm 0.11$ & $1.59 \pm 0.11$ & $1.51 \pm 0.08$ & 0.114 \\
\hline Simpson index of morphospecies & $0.66 \pm 0.04$ & $0.72 \pm 0.05$ & $0.70 \pm 0.05$ & 0.336 \\
\hline Chao-1 of OTUs & $46.50 \pm 2.54$ & $56.62 \pm 4.26$ & $32.65 \pm 6.68$ & 0.026 \\
\hline Sobs of OTUs & $42.80 \pm 2.85$ & $52.40 \pm 4.55$ & $31.60 \pm 6.22$ & 0.077 \\
\hline Shannon index of OTUs & $2.74 \pm 0.15$ & $2.90 \pm 0.07$ & $2.12 \pm 0.39$ & 0.160 \\
\hline Simpson index of OTUs & $0.10 \pm 0.02$ & 0.08 & $0.25 \pm 0.10$ & 0.154 \\
\hline
\end{tabular}

(4.64). Regarding the chemical properties, served in P12y soil, and the ALP activities of the soil fertility obviously increased with in- $\mathrm{P} 12 \mathrm{y}$ and $\mathrm{N}$ soils were the same (Tab. 1).

creasing age of the $B$. alnoides tree. P3y soil showed significantly lowest values for TN, TP, TK, AN, AP, AK and OM, whereas $\mathrm{N}$ soil presented the highest values for these properties except for TK. The $\mathrm{N}$ soil had the highest sand and silt contents, while P3y soil had the highest amount of clay. In relation to biological properties (enzyme activities), the lowest ALP, UE, CAT and SC activities were observed in $\mathrm{P}_{3} \mathrm{y}$ soil, the highest UE, CAT, SC activities were ob-

\section{AM fungal colonization and spore} density

Some typical structures of AMF that colonized the roots of $B$. alnoides of different ages are presented in Fig. 1. Overall, the level of root AMF colonization peaked at the intermediate stage (12 years), with root length colonization percentages of $25.32 \%$, $3.84 \%$ and $15.30 \%$ for hyphae, arbuscules and vesicles, respectively. The colonization percentages of naturally growing B. alnoides were the lowest among the three studied stands, with hyphal, arbuscule and vesicle colonization percentages of $7.54 \%$, $0.58 \%$ and $4.16 \%$, respectively. However, a significant difference among different stands was only detected for hyphal colonization ( $p=0.044-$ Tab. 2 ).

Along the chronosequence, the AMF spore density in rhizospheric soil increased from 51 spores in P3y to 98 spores in P12y and up to 225 spores per $20 \mathrm{~g}$ of air-dried soil in N (Tab. 2). However, the Kruskal-Wallis test did not detect a significant difference $(p=0.054)$.

\section{Morphological diversity of the $A M$ fungal community}

From the soil of the study plots, we identified 23 morphospecies belonging to 2 orders, 3 families and 4 genera, including 12 identified to the species level and 11 identified to the genus level (Tab. 3, Fig. 2). Glomus and Acaulospora were the most representative genera in the study area, with 10 and 8 species, respectively, followed by Scutellospora (4 species). The total richness of AMF from P3y, P12y and N was 12, 15 and 17 species, respectively. The fungal Shannon index and Simpson index values were highest in P21y, followed by N, and those of P3y were the lowest; however, the indexes were not significantly different $(p>0.05-$ Tab. 2).

In accordance with the NMDS permuta-

Tab. 3 - Relative abundance of AMF morphospecies in Betula alnoides rhizosphere soil of young and middle-aged plantations and adjacent native forest located in Puwen Tropical Forest Experimental Station, Xishuangbanna prefecture of Yunnan province, southwestern China. P3y, P12y and N represent 3-year-old saplings, 12-year-old stand and adjacent native forest, respectively. Data are expressed as the mean $\pm \operatorname{SE}(n=5)$. Differences at $p<0.05$ were considered statistically significant.

\begin{tabular}{|c|c|c|c|c|c|}
\hline Genus & Morphospecies & P3y & $\mathrm{P} 12 \mathrm{y}$ & N & $p$-value \\
\hline \multirow[t]{8}{*}{ Acaulospora } & Acaulospora bireticulata F.M. Rothwell\& Trappe & 0 & $0.17 \pm 0.17$ & 0 & 0.368 \\
\hline & Acaulospora capsicula B, aszk. & $6.73 \pm 2.32$ & $6.68 \pm 3.58$ & $20.48 \pm 8.80$ & 0.277 \\
\hline & Acaulospora foveataTrappe \& Janos & $3.13 \pm 3.13$ & $0.73 \pm 0.36$ & $0.48 \pm 0.21$ & 0.602 \\
\hline & Acaulospora koskei B,aszk. & 0 & 0 & $0.04 \pm 0.04$ & 0.368 \\
\hline & Acaulospora laevisGerd. \& Trappe & $6.33 \pm 4.98$ & $7.28 \pm 3.92$ & $3.44 \pm 1.54$ & 0.871 \\
\hline & Acaulospora sp. 1 & $0.63 \pm 0.63$ & 0 & 0 & 0.368 \\
\hline & Acaulospora sp. 2 & 0 & 0 & $0.11 \pm 0.11$ & 0.368 \\
\hline & Acaulospora sp. 3 & 0 & $0.17 \pm 0.17$ & 0 & 0.368 \\
\hline Gigaspora & Gigaspora sp. 1 & 0 & 0 & $0.17 \pm 0.17$ & 0.368 \\
\hline \multirow[t]{10}{*}{ Glomus } & Glomus flavisporum Trappe \& Gerd. & $27.08 \pm 4.71$ & $10.19 \pm 3.72$ & $4.75 \pm 2.39$ & 0.007 \\
\hline & Glomus fuegianum Trappe \& Gerd. & 0 & 0 & $0.40 \pm 0.40$ & 0.368 \\
\hline & Glomus macrocarpum Tul. \& C.Tul. & 0 & $6.79 \pm 3.51$ & $11.71 \pm 4.14$ & 0.027 \\
\hline & Glomus multicaule Gerd. \& B.K. Bakshi & $0.50 \pm 0.50$ & $33.65 \pm 10.14$ & $15.96 \pm 6.93$ & 0.005 \\
\hline & Glomus sp. 1 & $45.19 \pm 7.83$ & $14.54 \pm 6.35$ & $29.78 \pm 9.93$ & 0.065 \\
\hline & Glomus sp. 2 & $0.63 \pm 0.63$ & $0.69 \pm 0.33$ & $0.04 \pm 0.04$ & 0.325 \\
\hline & Glomus sp. 3 & $0.33 \pm 0.33$ & 0 & 0 & 0.368 \\
\hline & Glomus sp. 4 & 0 & $11.50 \pm 7.04$ & $0.11 \pm 0.11$ & 0.266 \\
\hline & Glomus sp. 5 & 0 & $0.09 \pm 0.09$ & $0.04 \pm 0.04$ & 0.581 \\
\hline & Glomus sp. 6 & 0 & 0 & $0.04 \pm 0.04$ & 0.368 \\
\hline \multirow[t]{4}{*}{ Sclerocystis } & Sclerocystis coremioides Berk. \& Broome & 0 & $1.20 \pm 1.20$ & 0 & 0.368 \\
\hline & Sclerocystis rubiformis Gerd. \& Trappe & $6.47 \pm 3.31$ & $5.97 \pm 1.83$ & $12.25 \pm 4.34$ & 0.403 \\
\hline & Sclerocystis sinuosa Gerd. \& B.K. Bakshi & $0.50 \pm 0.50$ & 0 & 0 & 0.368 \\
\hline & Sclerocystis sp. 1 & $2.50 \pm 2.50$ & $0.35 \pm 0.35$ & $0.20 \pm 0.16$ & 0.891 \\
\hline
\end{tabular}


Fig. 2 - AMF spores isolated from rhizosphere soils of Betula alnoides trees and morphological identification. (a) Acaulospora foveata; (b) Acaulospora laevis; (c) Acaulospora koskei; (d) Glomus multicaule; (e) (f) Sclerocystis sinuosa; (g) Sclerocystis rubiformis; (h) Glomus sp. 6; (i) Sclerocystis sp. 1; (j) Acaulospora sp. 3; (k) Glomus sp. 2; (I) Gigaspora sp. 1. (a)-(i): scale bar $=20 \mu \mathrm{m}$; (j)-(I): scale bar = $50 \mu \mathrm{m}$.
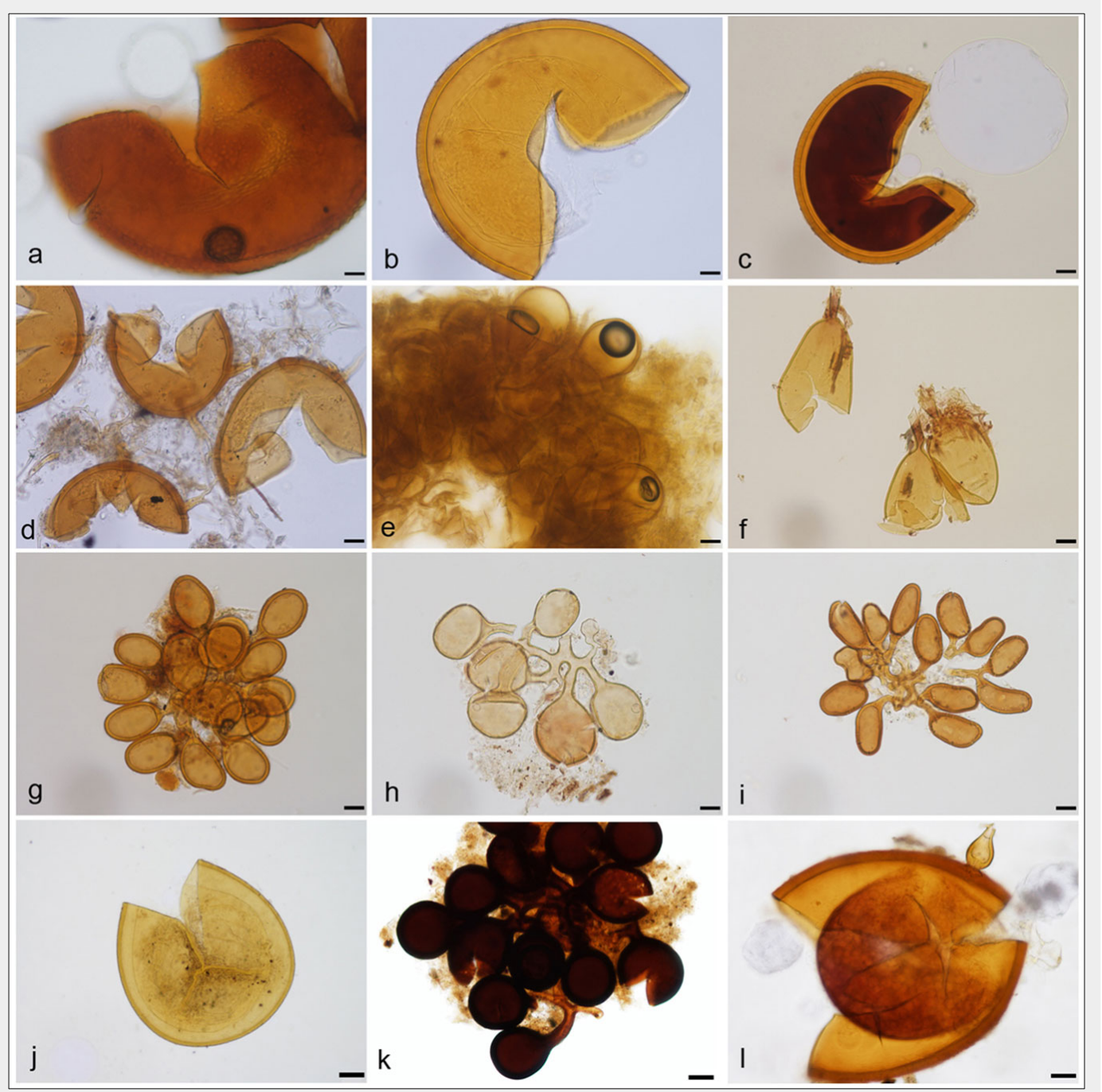

tion test on the relative abundance of dif- and Sclerocystis sp. 1. Three taxa, namely,

ferent morphological taxa, there was no Acaulospora sp. 1, Glomus sp. 3 and S. sinuclear separation of the AM fungal community composition of P3y, P12y and N. Only Glomus flavisporum $(p=0.007)$, G. macrocarpum $(p=0.027)$ and $G$. multicaule $(p=$ 0.005 ) showed different abundances of AMF spores among the studied stands (Tab. 3).

Nine taxa were recorded in all three plots: Acaulospora capsicula, A. foveata, A. laevis, G. flavisporum, G.multicaule, Glomus sp. 1, Glomus sp. 2, Sclerocystis rubiformis osa, occurred only in P3y; three taxa, namely, A. bireticulata, Acaulospora sp. 3 and S. coremioides occurred only in P12y; and five taxa, namely, A. koskei, Acaulospora sp. 2, Glomus fuegianum, Glomus sp. 6 and Gigaspora sp. 1, occurred only in $\mathrm{N}$.

AM fungal community composition assessed by Illumina MiSeq sequencing

A total of 269,130 sequences were obtained from all 15 samples from Illumina
MiSeq ${ }^{\circledR}$ sequencing after quality control, and a total of 119 OTUs were detected based on $97 \%$ similarity (Tab. S1 in Supplementary material). All sequences belonged to the phylum Glomeromycota, including ten genera, namely, Archaeospora, unclassified Archaeosporaceae, Acaulospora, Redeckera, Scutellospora, unclassified Gigasporaceae, Gigaspora, Glomus, Paraglomus and unclassified Glomeromycetes. With increasing read numbers, the species accumulation curves (Fig. S1 in Supplementary material) tended to reach a saturation
Fig. 3 - Non-metric multidimensional scaling (NMDS) plots showing the correlations between AM fungal community and soil characteristics. NMDS permutation test on OTU abundance (a) and on the relative abundance of different morphological taxa (b). Physicochemical correlations are shown with lines. The length of lines indicates the relative importance of that variable in explaining the variation in $A M$ fungal community composition, while the angle between arrows indicates the degree to which they are correlated.
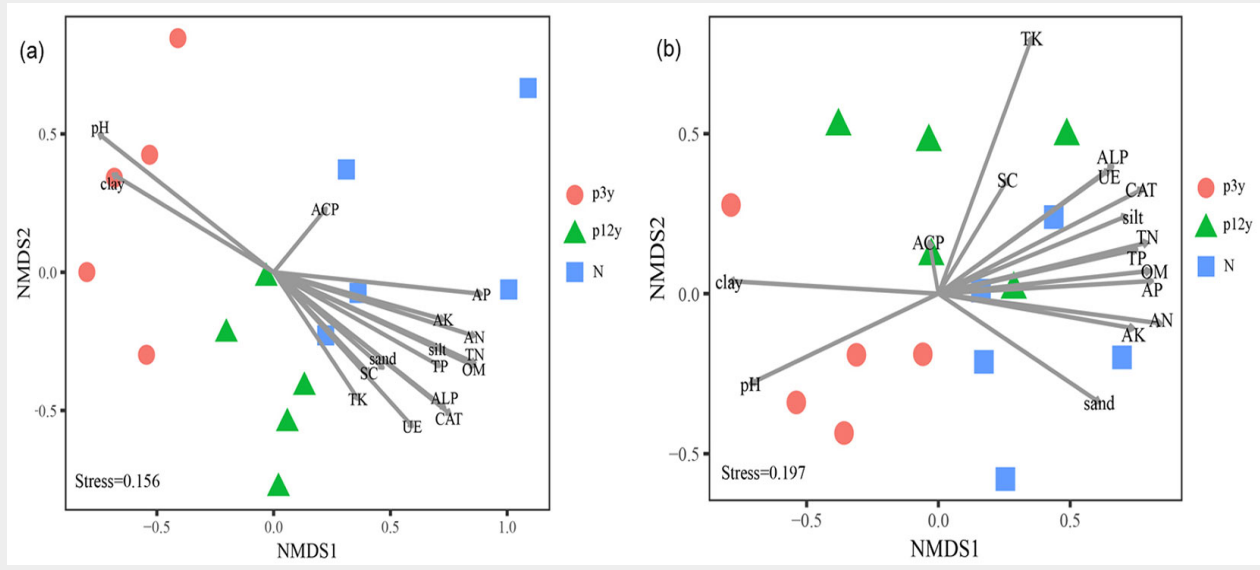


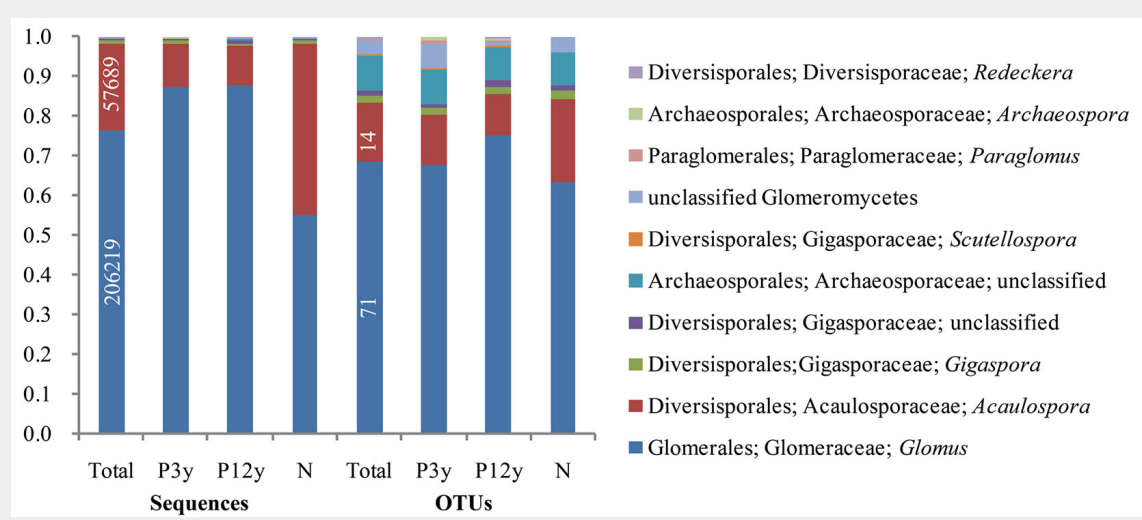

Fig. 4 - Proportional distributions of the sequences and operational taxonomic units (OTUs) in the phylum Glomeromycota among the total, P3y, P12y and N samples. P3y, $\mathrm{P} 12 \mathrm{y}$ and $\mathrm{N}$ represent 3-year-old sapling, 12-year-old stand and adjacent native forest, respectively.

Tab. 4 - Mantel test of relationships of AM fungal community composition of Betula alnoides stands with soil characteristics. (TN): total nitrogen; (TP): total phosphorus; (TK): total potassium; (AN): available nitrogen; (AP): available phosphorus; (AK): available potassium; (OM): organic matter; (ACP): acid phosphatase activity; (ALP): alkaline phosphatase activity; (UE): urease activity; (CAT): catalase activity; (SC): sucrase activity. Values in italics indicate significant correlations $(p<0.05)$.

\begin{tabular}{|ccc}
\hline \multirow{2}{*}{ Variable } & \multicolumn{2}{c}{ AM fungal community } \\
\hline & Mantel $r$ & $p$ value \\
\hline pH & 0.1536 & 0.2150 \\
\hline TN & 0.3259 & 0.0170 \\
\hline TP & 0.1342 & 0.3490 \\
\hline TK & -0.0520 & 0.7650 \\
\hline AN & 0.3076 & 0.0040 \\
\hline AP & 0.5774 & 0.0010 \\
\hline AK & 0.3069 & 0.0800 \\
\hline OM & 0.3326 & 0.0060 \\
\hline ACP & 0.1032 & 0.4100 \\
\hline ALP & 0.1045 & 0.3670 \\
\hline UE & 0.0780 & 0.6620 \\
\hline CAT & 0.1465 & 0.1910 \\
\hline SC & -0.0995 & 0.5700 \\
\hline sand & 0.0061 & 0.9840 \\
\hline silt & 0.2426 & 0.0220 \\
\hline clay & 0.2029 & 0.1310 \\
\hline
\end{tabular}

Fig. 5 - Hierarchical cluster analysis based on the OTU similarity of AM fungal communities from P3y, P12y and N. P3y, P12y and N represent 3year-old saplings, 12-year-old stand and adjacent native forest, respectively.

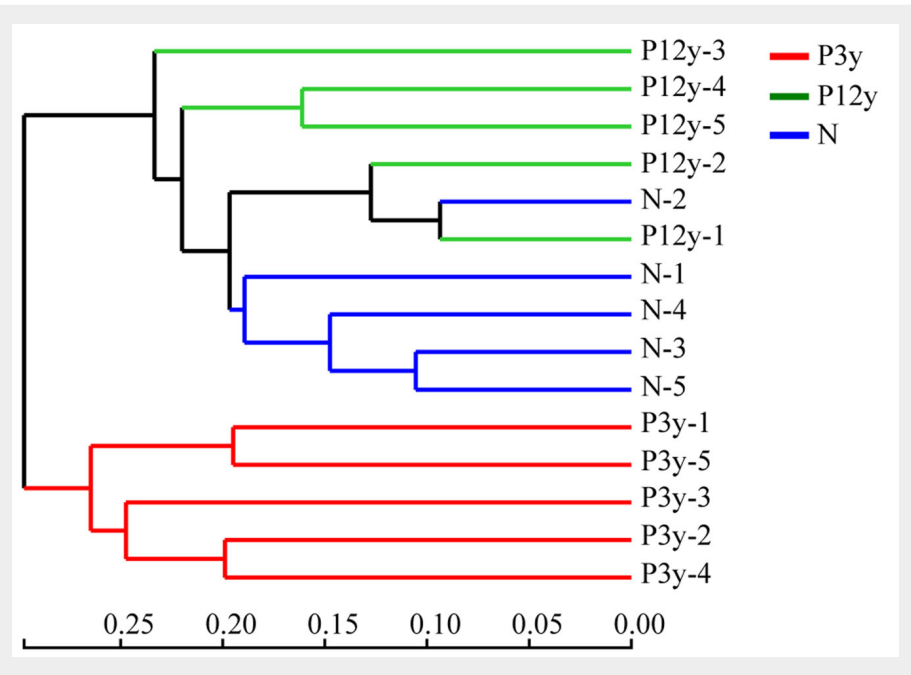

plateau, indicating that the sampling intensity was sufficient.

Nine, 10, and 6 genera were detected from P3y, P12y and N, respectively (Tab. S2 in Supplementary material). Based on Illumina $\mathrm{MiSeq}^{\oplus}$ sequencing, the diversity indexes of Chao-1, Sobs and Shannon index peaked in P12y, followed by P3y, and those of $\mathrm{N}$ were the lowest. Nevertheless, only the difference in Chao-1 was significant ( $p=$ 0.026 - Tab. 2).

The NMDS permutation test resulted in a clear separation of the AM fungal community composition of $\mathrm{P}_{3 y}, \mathrm{P}_{12} \mathrm{y}$ and N (Fig. 3a). This observation was further confirmed by the PERMANOVA test $(F=7.2688$, $p=0.001-$ Tab. S3 in Supplementary material). The 3 stands shared Glomus, Acaulospora, Gigaspora, unclassified Gigasporaceae, unclassified Archaeosporaceae and unclassified Glomeromycetes. Glomus was the most dominant genus in all 3 stands, with sequence proportions of $87.31 \%$, $87.56 \%$ and $55.00 \%$ in $\mathrm{P}_{3 y}, \mathrm{P}_{12} \mathrm{y}$ and $\mathrm{N}$, followed by Acaulospora, with proportions of $11.01 \%, 10.17 \%$ and $43.12 \%$ in P3y, P12y and N, respectively; Redeckera was detected only in P12y. Three taxa, namely, Archaeospora, Scutellospora and Paraglomus, were shared by $\mathrm{P}_{3 y}$ and $\mathrm{P}_{12} \mathrm{y}$ and were not found in $\mathrm{N}$ (Fig. 4 - Tab. S2 in Supplementary material).

Hierarchical cluster analysis concerning the number and abundance of OTUs showed that the AMF communities of 15 samples were divided into two distinct clusters, one cluster contained only the five samples of $\mathrm{P}_{3} \mathrm{y}$. In contrast, the other cluster included the five samples of P12y and five samples of $\mathrm{N}$, showing a high degree of similarity of AMF communities from these two study stands (Fig. 5).

\section{AM fungal attributes and community composition in relation to soil characteristics}

Considering the AM fungal attributes, including AM colonization, spore density and diversity indexes, including morphological and molecular, the Kruskal-Wallis test only found significant differences among different study stands on two attributes, namely, colonization percentage of AMF hyphae $(p=0.044)$ and Chao- 1 index of OTUs in the molecular analysis ( $p=0.026-$ Tab. 2$)$.

Neat clustering was not apparent in the morphological analysis of AM fungal communities on the relative abundance of different taxa (Fig. 3b), and significant dissimilarity between different study stands was not observed (PERMANOVA test $r^{2}=0.1320$, $F=1.9775, p=0.1480-$ Tab. S3 in Supplementary material).

The variation in $A M$ fungal community composition based on OTUs was positively correlated with a series of parameters, including soil AP, AK, AN, TN, TP, TK, OM, silt, sand, ALP, CAT, UE and SC along axis NMDS1, whereas $\mathrm{pH}$ and clay were positively correlated with variation along axis NMDS2 (Fig. 3a). Furthermore, to compare 
the effects of variables on the AM fungal community composition, Mantel tests were conducted. AP had the most substantial effect on the community $(p=0.001)$, and $\mathrm{AN}, \mathrm{OM}, \mathrm{TN}$, and silt content also significantly influenced the AM fungal community composition (Tab. 4).

\section{Discussion}

The present study was the first to explore the $A M$ symbiosis of $B$. alnoides in both plantations and natural stand and to compare AM fungal community composition among young sapling, middle-aged and mature natural growing $B$. alnoides in tropical ecosystems of Xishuangbanna, Yunnan Province, southwestern China. Thus, it is the first step in understanding the ecological aspects of AM fungal communities in $B$. alnoides plantations and the first step towards the management of AM fungal communities aiming at improving the plantation soil quality and health as a whole.

\section{Primary status of $A M$ of $B$. alnoides stands at different ages}

The results indicated that among the AM fungal attributes studied, hyphal colonization in roots and the Chao- 1 index of AMF OTUs in rhizosphere soil differed among the three studied stands; those in P12y were the highest, followed by $\mathrm{P}_{3 y}$, and the lowest was $\mathrm{N}$. This result could be explained considering the nutrient-rich conditions of the natural stand; sufficient mineral nutrients may be taken up by plants from the soil without the help of AMF, leading to a gradual reduction in the dependency of plants on AMF (Liu et al. 2017). The higher root AMF colonization of middle-aged $B$. alnoides trees in our study was similar to that reported by Sheng et al. (2017) of black locust (Robinia pseudoacacia) plantations. Sheng et al. found that the AMF colonization of black locust tree roots in plantations along a chronosequence of $11,23,35$ and 46 years of age showed a hump-shaped variation, peaking at an intermediate stage of 35 years. Moreover, AMF have different life strategies (Herrmann et al. 2016); for instance, Glomus species are known as competitive root colonizers since they can colonize roots from spores (Herrmann et al. 2016). The experiment on Plantago lanceolata showed that Claroideoglomus species could colonize roots profusely and form numerous arbuscules and hyphal coils (Blaszkowski et al. 2015). In this study, the $B$. alnoides trees at different ages harbored distinct AMF groups, which might partly explain the divergence of AMF colonization in roots.

$A M F$ spore density in rhizosphere soil AMF spore densities recorded from 51 spores/20 g air-dried soil to 225 spores/20 g air-dried soil in this study were comparable to those observed from the tropics (Birhane et al. 2018). AMF spores are resting structures that are involved in "long-term" survival, and their abundance varies with the sporulation rates of different species and has also been found to be closely related to host plants (Diop et al. 1994, Bever et al. 1996).

In our study, the spore density increased over a chronosequence from 3 years old to 12 years old and in natural stand with long growing time and denser vegetation cover. These results appear to contradict those of Birhane et al. (2018), who observed a low spore density in dense vegetation cover and significantly higher spore density in poor vegetation cover but agree with the findings of Sheng et al. (2017), who found a linear increase in spore abundance in black locust (Robinia pseudoacacia) plantations over a chronosequence from 11 to 46 years. In our study, the low AMF spore density in 3-year-old plantation could be attributed to disturbances in the soil due to vegetation removal during land preparation before planting $B$. alnoides seedlings, as AMF availability and activity can be affected by tillage or soil preparation, which can result in a significant decrease in spore density (De Pontes et al. 2017).

\section{AM fungal community diversity and composition}

A total of 9, 10 and 6 AM fungal genera were identified in $\mathrm{P}_{3 y}, \mathrm{P}_{12} \mathrm{y}$ and $\mathrm{N}$ by Illumina MiSeq sequencing, respectively. However, based on spore morphological identification, 12, 15 and 17 species belonging to four genera, namely, Acaulospora, Glomus, Gigaspora and Sclerocystis, were detected. Variation in the sporulation rate of different AMF species might explain the different findings between the morphological and molecular analyses since morphology depended on spore surveys in rhizosphere soil. In contrast, the molecular method could be used to detect all the AMF propagules, including spores, hyphae and AMFinfected rootlets of the host plant. Nevertheless, to more thoroughly assess AMF community diversity, it is necessary to associate classical taxonomic evaluations with molecular biological techniques (Júnior et al. 2019). An accurate depiction of the AM fungal community could be obtained by Illumina MiSeq ${ }^{\circledast}$ sequencing since a tremendous amount of amplicon data can be collected with this technique (Liu et al. 2017). In contrast, morphological studies can accumulate propagules, which are necessary for studying the application of AMF in the following step.

AMF species richness was high in plantations, pointing to a broader range of niches and opportunities in these study plots. Similar results were obtained by Reyes et al. (2019), who compared the morphospecies of AMF in 3-4-year-old and 6-8-year-old degraded secondary forests with mature rainforests and found that both the species richness and Shannon index of degraded secondary forest regrowth were significantly higher than those of mature rainforests. They thus concluded that the resilience of secondary forests was high and excellent, and this kind of resilience was also confirmed by the study of reforestation plots on degraded pastures in South Ecuador (Haug et al. 2010). Likewise, in our study, B. alnoides plantations did not significantly reduce the $A M$ fungal community diversity, and resilience was not low in B. alnoides plantations compared with neighboring natural forest. Moreover, with increasing stand age, the AMF fungal communities showed a noticeable development trend towards the natural stand. However, the distinct composition of the natural stand itself revealed the considerable potential for AMF diversity conservation, suggesting the crucial importance of protecting pristine tropical forests.

The results of our study, including both the morphological identification of spores and molecular analysis, showed that Glomus and Acaulospora were the dominant taxa. These two genera have a high prevalence in most ecosystems (Da Silva et al. 2015, De Pontes et al. 2017, Pereira et al. 2018), which is possibly due to the high adaptability of these AM fungal groups to different plant hosts, soil types, climatic conditions and other environmental characteristics (Vieira et al. 2019).

Regarding the proportion of specific genera, the results of Illumina MiSeq ${ }^{\oplus}$ sequencing revealed that the proportions of Glomus sequences in $\mathrm{P} 3 y$ and $\mathrm{P} 12 \mathrm{y}$ were $87.31 \%$ and $87.56 \%$, respectively, showing the absolute position. In contrast, in the natural stand, Glomus sequences had a proportion of $55.00 \%$, which was not as significantly dominant as that in plantations. Glomus taxa are thought to be resistant to many kinds of disturbances (Chagnon et al. 2013), which might partly explain the higher proportion of this group in plantations.

\section{Soil characteristics driving AM fungal communities}

The influences of climate, soil and plant communities on AMF communities are well documented (Antunes et al. 2011, Sheng et al. 2017, Melo et al. 2017). Although many researchers have reported that soil impacts AMF diversity, there is no consistent conclusion. Some authors have reported that soil texture has a more significant influence on the AMF community than soil chemical properties (Da Silva et al. 2015, Duarte et al. 2019). However, other studies have found that while soil chemistry does modify the AMF community, soil texture does not appear to do so (Pagano et al. 2013).

In the present study, soil pH, AP, AK, AN, TN, TP, OM, silt, sand, clay, ALP, CAT, UE, SC and TK differed significantly among the three studied stands. These factors are vital in shaping AM fungal communities in different natural ecosystems (Lin et al. 2012, Xiang et al. 2014, Reyes et al. 2019). However, which factors principally contribute to the differences in AM fungal communities in different stands is of critical concern. We revealed that AP was the main driving factor of the AM fungal communi- 
ties among different stands. Phosphorus uptake is considered the primary role of AM fungal symbionts. However, high phosphorus availability can reduce the dependency of plants on AMF (Lin et al. 2012), which may decrease the carbohydrate supply from plants for AMF in roots and lead to a decline in the fungal community (Liu et al. 2017). In addition to available phosphorus, the Mantel test revealed that TN, AN, $\mathrm{OM}$ and silt content were the explanatory variables that significantly shaped the AMF communities in our study.

\section{Conclusions}

The results of the present study provide a general picture of the composition of the AM fungal community at different growth stages of B. alnoides stands in Xishuangbanna, a tropical area in Yunnan Province, China. The roots of Betula alnoides trees at different ages were typically colonized by AMF. In the rhizosphere soil of plantation stands, we detected diverse but distinct AM fungal communities compared with that of neighboring natural stand. AMF showed considerable resilience to the establishment of the $B$. alnoides plantation, wherein the 12-year-old plantation harbored AM fungal communities more similar to those in the natural stand than those in the 3-year-old plantation. This implies that along with the growth of plantation, which is driven by the improvement in environmental factors such as soil parameters, especially available phosphorus, available nitrogen, organic matter, total nitrogen and silt content, the AM fungal diversity and community composition could develop towards and close to the state of the natural forest. The importance of natural forest conservation is considerable since it harbored unique AMF composition and diversity. Evaluation of the mycorrhizal status and variation of AM fungal communities is only a first step for providing some information to improve the management of $B$. alnoides plantations; ideally, future research should be aimed at screening for suitable AMF species and practical technology, which are crucial for efficient planting and sustainable management of $B$. alnoides plantations.

\section{Acknowledgments}

The authors thank Liqun Yang, Feng'e Zhang and Shuming Zhang for their assistance in samples collection and some laboratory work. This work was financially supported by Technological Innovation Talents Raising Foundation of Yunnan Province (2012HB053); Young Academic and Technical Leader Raising Foundation of Yunnan Province (2011Cl027); and Tropical and Subtropical Precious Timber Species Innovation Research Team Construction Project of Yunnan Province (2017HC024).

\section{Author contributions}

Yuebo Jing and Tao Li contributed equally to this work.

\section{References}

Antunes PM, Koch AM, Morton JB, Rillig MC, Klironomos JN (2011). Evidence for functional divergence in arbuscular mycorrhizal fungi from contrasting climatic origins. New Phytologist 189: 507-514. - doi: 10.1111/j.1469-8137.2010.0 3480.x

Bever JD, Morton JB, Antonovics J, Schultz PA (1996). Host-dependent sporulation and species diversity of arbuscular mycorrhizal fungi in a mown grassland. Journal of Ecology 84: 71-82. - doi: 10.2307/2261701

Birhane E, Fatumah N, Gidey K, Zenebe A, Mohammed $S$ (2018). Vegetation cover density and disturbance affected arbuscular mycorrhiza fungi spore density and root colonization in a dry Afromontane forest, northern Ethiopia. Journal of Forestry Research 29: 675-686. - doi: 10.1007/s11676-017-0493-5

Blaszkowski J, Chwat G, Bence Góralska K A (2015). Acaulospora ignota and Claroideoglomus hanlinii, two new species of arbuscular mycorrhizal fungi (Glomeromycota) from Brazil and Cuba. Mycological Progress 14: 18. - doi: 10.1007 /s11557-015-1042-2

Brundrett MC, Tedersoo L (2018). Evolutionary history of mycorrhizal symbioses and global host plant diversity. New Phytologist 220: 11081115. - doi: 10.1111/nph.14976

Cao M, Zou XM, Warren M, Zhu H (2006). Tropical forests of Xishuangbanna, China. Biotropica 38: 306-309. - doi: 10.1111/j.1744-7429.2006.0014 6.x

Chagnon PL, Bradley RL, Maherali H, Klironomos JN (2013). A trait-based framework to understand life history of mycorrhizal fungi. Trends in Plant Science 18: 484-491. - doi: 10.1016/j.tplan ts.2013.05.001

Chen HW, Li J, Zhou B, Feng X, Meng M, Liu YG, Wang DM (2006). Comparison of community characteristics between artificial Betula alnoides forest and mountainous rain forest in Xishuangbanna of Yunnan Province, Chinese Bulletin of Botany 23: 169-176. [in Chinese with English Abstract] - doi: 10.3969/j.issn.1674-3466.2006. 02.007

Da Silva DKA, De Souza RG, De Alencar Velez BA, Da Silva GA, Oehl F, Maia LC (2015). Communities of arbuscular mycorrhizal fungi on a vegetation gradient in tropical coastal dunes. Applied Soil Ecology 96: 7-17. - doi: 10.1016/j.apsoil. 2015.06.009

De Pontes JS, Oehl F, Pereira CD, De Toledo Machado CT, Coyne D, Da Silva DKA, Maia LC (2017). Diversity of arbuscular mycorrhizal fungi in the Brazilian's Cerrado and in soybean under conservation and conventional tillage. Applied Soil Ecology 117-118: 178-189. - doi: 10.1016/j.ap soil.2017.04.023

Diop TA, Gueye M, Dreyfus BL, Plenchette C, Strullu DG (1994). Indigenous arbuscular mycorrhizal fungi associated with Acacia albida Del. in different areas of Senegal. Applied and Environmental Microbiology 60: 3433-3436. - doi: 10.1002/bit.260440613

Du S, Gao XZ, Ma CB, Shen T, Bai YL, Ye DX, Zhu L, Sun Z, Guan YY, Jiang RF, Li K, Yang F, Yang SY, Zhang YF, Su YH, Shao H, Quan WJ (2006). Technical specification for soil analysis. China Agriculture Press, Beijing, pp. 256.

Duarte LM, Bertini SCB, Stürmer SL, Lambais
MR, Azevedo LCB (2019). Arbuscular mycorrhizal fungal communities in soils under three phytophysiognomies of the Brazilian Atlantic Forest. Acta Botanica Brasilica 33: 50-60. - doi: 10.1590/0102-33062018abb0236

Gerdemann JW, Nicolson TH (1963). Spores of mycorrhizal Endogone species extracted from soil by wet sieving and decanting. Transactions of the British Mycological Society 46: 235-244. doi: 10.1016/Soo07-1536

Gong MQ, Wang FZ, Chen Y, Chen YL (2000). Mycorrhizal dependency and inoculant effects on the growth of Betula alnoides seedlings. Forest Research 13: 8-14. [in Chinese with English Abstract] - doi: 10.3321/j.issn:1001-1498.2000.01.00 2

Goslee SC, Urban DL (2007). The ecodist package for dissimilarity-based analysis of ecological data. Journal of Statistical Software 22: 1-19. - doi: 10.18637/jss.v022.io7

Guo YJ, Han JG (2008). Soil biochemical properties and arbuscular mycorrhizal fungi as affected by afforestation of rangelands in northern China. Journal of Arid Environments 72: 1690-1697. - doi: 10.1016/j.jaridenv.2008.04.001 Hansen MC, Potapov PV, Moore R, Hancher M, Turubanova SA, Tyukavina A, Thau D, Stehman SV, Goetz SJ, Loveland TR, Kommareddy A, Egorov A, Chini L, Justice CO, Townshend JRG (2013). High-resolution global maps of 21st-century forest cover change. Science 342: 850-853. - doi: 10.1126/science.1244693

Haug I, Wubet T, Weiß M, Aguirre N, Weber M, Günter S, Kottke I (2010). Species-rich but distinct arbuscular mycorrhizal communities in reforestation plots on degraded pastures and in neighboring pristine tropical mountain rain forest. Tropical Ecology 51: 125-148. - doi: 10.1016/j. tree.2010.08.011

Herrmann L, Lesueur D, Bräu L, Davison J, Jairus T, Robain H, Robin A, Vasar M, Wiriyakitnateekul W, Opik M (2016). Diversity of root-associated arbuscular mycorrhizal fungal communities in a rubber tree plantation chronosequence in Northeast Thailand. Mycorrhiza 26: 863-877. - doi: 10.1007/s00572-016-0720-5 Jacobs DF, Oliet JA, Aronson J, Bolte A, Bullock JM, Donoso PJ, Landhäusser SM, Madsen P, Peng SL, Rey-Benayas JM, Weber JC (2015). Restoring forests: what constitutes success in the twenty-first century? New Forest 46 (5-6): 601-604. - doi: 10.1007/s11056-015-9513-5

Jiang YD, Zhou FL, Zhou Y, Chen HW, Zhang KF, Liu YG, Li J (1999). Study on change law of soil nutrient content in Betula alnoides plantation. Yunnan Forestry Science and Technology 87: 27-31. [in Chinese with English Abstract] Júnior PP, Moreira BC, Da Silva MDCS, Veloso TGR, Stürmer SL, Fernandes RBA, Mendonça EDS, Kasuya MCM (2019). Agroecological coffee management increases arbuscular mycorrhizal fungi diversity, PLoS One 14: e0209093. doi: 10.1371/journal.pone.0209093

Lee J, Lee S, Young JPW (2008). Improved PCR primers for the detection and identification of arbuscular mycorrhizal fungi. FEMS Microbiology Ecology 65: 339-349. - doi: 10.1111/j.1574-69 41.2008.00531.x

Li J, Chen HW, Feng X (2003). Carbon stock and rate of carbon sequestration assessment of hardwood plantations in tropical Yunnan, 
China. Guihaia 23: 294-298. [in Chinese with English Abstract] - doi: 10.3969/j.issn.1000-3142. 2003.04.002

Lin XG, Feng YZ, Zhang HY, Chen RR, Wang JH, Zhang JB, Chu HY (2012). Long-term balanced fertilization decreases arbuscular mycorrhizal fungal diversity in an arable soil in North China revealed by 454 pyrosequencing. Environmental Science and Technology 46: 5764-5771. - doi: 10.1021/es3001695

Liu M, Zheng R, Bai SL, Bai Y, Wang JG (2017). Slope aspect influences arbuscular mycorrhizal fungus communities in arid ecosystems of the Daqingshan Mountains, Inner Mongolia, North China. Mycorrhiza 27: 189-200. - doi: 10.1007/s 00572-016-0739-7

Lumini E, Orgiazzi A, Borriello R, Bonfante P, Bianciotto V (2010). Disclosing arbuscular mycorrhizal fungal biodiversity in soil through a land-use gradient using a pyrosequencing approach. Environmental Microbiology 12: 21652179. - doi: 10.1111/j.1462-2920.2009.02099.x McGonigle TP, Miller MH, Evans DG, Fairchild GL, Swan JA (1990). A new method which gives an objective measure of colonization of roots by vesicular-arbuscular mycorrhizal fungi. New Phytologist 115: 495-501. - doi: 10.1111/j.1469-813 7.1990.tboo476.x

Melo CD, Luna S, Krüger C, Walker C, Mendonça D, Fonseca HMAC, Jaizme-Vega M, Machado ADC (2017). Arbuscular mycorrhizal fungal community composition associated with Juniperus brevifolia in native Azorean forest. Acta Oecologica 79: 48-61. - doi: 10.1016/j.actao.2016.12.0 06

Meng $M$, Chen HW, Liu YG, Feng $X$, Wang DM, Li LF, Zhou Y (2002). Water conservation function of Betula alnoides and Paramichelia baillonii plantations of Xishuangbanna. Yunnan Forestry Science and Technolgy 100: 46-49. [in Chinese with English Abstract]

Oksanen J, Blanchet GF, Kindt R, Legendre P, Minchin PR, O'Hara RB, Simpson GL, Solymos P, Stevens HH, Wagner H (2013). vegan: community ecology package. R Package Version 2.0.10. [online] URL: http://CRAN.R-project.org/pack age=vegan

Opik M, Vanatoa A, Vanatoa E, Moora M, Davison J, Kalwij JM, Reier U, Zobel M (2010). The online database Maarj AM reveals global and ecosystemic distribution patterns in arbuscular mycorrhizal fungi (Glomeromycota). New Phytologist 188: 223-241. - doi: 10.1111/j.1469-8137. 2010.03334.x

Pagano MC, Utida MK, Gomes EA, Marriel IE, Cabello MN, Scotti MR (2011). Plant-type dependent changes in arbuscular mycorrhizal communities as soil quality indicator in semi-arid Brazil. Ecological Indicators 11: 643-650. - doi: 10.1016/j.ecolind.2010.09.001

Pagano MC, Zandavalli RB, Araújo FS (2013). Biodiversity of arbuscular mycorrhizas in three vegetational types from the semiarid of Ceará State, Brazil. Applied Soil Ecology 67: 37-46. doi: 10.1016/j.apsoil.2013.02.007

Pereira APDA, Santana MC, Bonfim JA, Mescolotti DDL, Cardoso EJBN (2018). Digging deeper to study the distribution of mycorrhizal arbuscular fungi along the soil profile in pure and mixed Eucalyptus grandis and Acacia mangium plantations. Applied Soil Ecology 128: 1-11. - doi: 10.1016/j.apsoil.2018.03.015

Redecker D, Schüler A, Stockinger H, Stürmer SL, Morton J, Walker C (2013). An evidence-based consensus for the classification of arbuscular mycorrhizal fungi (Glomeromycota). Mycorrhiza 23: 515-531. - doi: 10.1007/s00572-013-0486-y Reyes HA, Ferreira PFA, Silva LC, Da Costa MG, Nobre CP, Gehring C (2019). Arbuscular mycorrhizal fungi along secondary forest succession at the eastern periphery of Amazonia: seasonal variability and impacts of soil fertility. Applied Soil Ecology 136: 1-10. - doi: 10.1016/j.apsoil.2018. 12.013

Rillig MC, Mummey DL (2006). Mycorrhizas and soil structure. New Phytologist 171: 41-53. - doi: 10.1111/j.1469-8137.2006.01750.x

Schenck NC, Pérez Y (1990). Manual for the identification of VA mycorrhizal fungi. Synergistic Publications, Gainesville, USA, pp. 283.

Sheng $M$, Chen XD, Zhang XL, Hamel C, Cui XW, Chen J, Chen H, Tang $M$ (2017). Changes in arbuscular mycorrhizal fungal attributes along a chronosequence of black locust (Robinia pseudoacacia) plantations can be attributed to the plantation-induced variation in soil properties. Science of the Total Environment 599-600: 273283. - doi: 10.1016/j.scitotenv.2017.04.199

Singer M J, Janitzky P (1986). Field and Laboratory procedures used in a soil chronosequence study. USGS Bulletin 1648, US Government Printing Office, Washington, DC, USA, pp. 49. [online] URL: http://books.google.com/books? id=srX1bwzRjRcC

Smith SE, Read D (2008). Mycorrhizal Symbiosis ( $3^{\text {rd }}$ edn). Academic Press, Amsterdam, Netherlands, pp. 800.

Van Der Heijden MGA, Klironomos JN, Ursic M, Moutoglis P, Streitwolf-Engel R, Boller T, Wiemken A, Sanders IR (1998). Mycorrhizal fungal diversity determines plant biodiversity, ecosystem variability and productivity. Nature 396: 69-72. - doi: 10.1038/23932

Vieira LC, Da Silva DKA, Da Silva IR, Gonçalves CM, De Assis DMA, Oehl F, Da Silva GA (2019). Ecological aspects of arbuscular mycorrhizal fungal communities in different habitat types of a Brazilian mountainous area. Ecological Research 34: 182-192. - doi: 10.1111/1440-1703.1061 Wang CS, Hein S, Zhao ZG, Guo JJ, Zeng J (2016). Branch occlusion and discoloration of Betula alnoides under artificial and natural pruning. Forest Ecology and Management 375: 200-210. doi: 10.1016/j.foreco.2016.05.027

Wang DM, Feng $X$, Wang $Q H$, Zhang KF, Chen HW (2003). Study on growing proceeding of Betula alnoides plantation. Guangxi Forestry Science 32: 17-19. [in Chinese with English Abstract] - doi: 10.3969/j.issn.1006-1126.2003.01. 004

Xiang D, Verbruggen E, Hu YJ, Veresoglou SD, Rillig MC, Zhou WP, Xu TL, Li H, Hao ZP, Chen YL, Chen BD (2014). Land use influences arbuscular mycorrhizal fungal communities in the farmingpastoral ecotone of northern China. New Phytologist 204: 968-978. - doi: 10.1111/nph.12961

\section{Supplementary Material}

Tab. S1 - Sequences numbers and derived OTUs in the present study.

Tab. S2 - Numbers of sequences (A) and derived OTUs (B) in the genus of Glomeromycota in different study plots.

Tab. S3 - Permutation test for adonis under reduced model.

Fig. S1 - Rarefaction curve of Sobs OTU index for different study stands.

Link: Jing_3515@supploo1.pdf 